\title{
BMJ Open Healthcare system maturity for integrated care: results of a Swiss nationwide survey using the SCIROCCO tool
}

\author{
Isabelle Peytremann-Bridevaux (D) , ${ }^{1}$ Séverine Schusselé Filliettaz (1) , ${ }^{2,3}$ \\ Peter Berchtold, ${ }^{3}$ Michelle Grossglauser, ${ }^{1}$ Andrea Pavlickova, ${ }^{4}$ Ingrid Gilles ${ }^{1}$
}

To cite: PeytremannBridevaux I, Schusselé Filliettaz S, Berchtold P, et al. Healthcare system maturity for integrated care: results of a Swiss nationwide survey using the SCIROCCO tool. BMJ Open 2021;11:e041956. doi:10.1136/ bmjopen-2020-041956

- Prepublication history and supplemental material for this paper is available online. To view these files, please visit the journal online (http://dx.doi. org/10.1136/bmjopen-2020041956).

Received 24 June 2020 Revised 22 December 2020 Accepted 12 January 2021

Check for updates

(C) Author(s) (or their employer(s)) 2021. Re-use permitted under CC BY-NC. No commercial re-use. See rights and permissions. Published by BMJ.

${ }^{1}$ Center for Primary Care and Public Health (Unisanté), University of Lausanne, Lausanne, Switzerland

${ }^{2}$ Association for the promotion of integrated patient care networks (PRISM), Geneva, Switzerland

${ }^{3}$ Swiss Forum for Integrated Care (FMC), Bern, Switzerland ${ }^{4}$ Technology Enabled Care and Digital Healthcare Innovation, National Services Scotland (NHS), Edinburgh, UK

\section{Correspondence to}

Professor Isabelle PeytremannBridevaux;

isabelle.peytremann-

bridevaux@unisante.ch

\section{ABSTRACT}

Objectives To assess the maturity of the Swiss healthcare system for integrated care and to explore whether this maturity varied according to several variables.

Design A Swiss nationwide individual electronic survey in November 2019.

Setting and population Stakeholders identified via lists of the Swiss Forum for Integrated Care and of the integrated care unit of the Swiss Federal Office of Public Health, and representatives of 26 cantonal public health departments, were invited to participate.

Primary outcome measure The outcome was the maturity of the Swiss healthcare system for integrated care, measured with the Scaling Integrated Care in Context maturity model tool (SCIROCCO tool), which comprises 12 dimensions and questions rated on a 6-point scale. Analysis Univariate analyses were first performed, followed by bivariate analyses, to find out whether maturity varied according to working linguistic region, healthcare profession, main domain of professional activity, implication in integrated care, attitude towards integrated care and attitude towards the Swiss healthcare system. Results The 642 respondents were 53.7 years on average, $42.5 \%$ were women, $60.0 \%$ and $20.7 \%$ worked in the German and French-speaking parts of Switzerland, respectively. Overall, the maturity of the Swiss healthcare system for integrated care was evaluated as low, with dimension means ranging from 1.0 $( \pm 1.0)$ for the 'Funding' dimension to a maximum of $2.7( \pm 1.1)$ for 'eHealth Services'. Results only varied according to the working linguistic region.

Conclusions Results highlight a limited maturity of the Swiss healthcare system for integrated care, as assessed at a national level by a large and varied number of healthcare stakeholders. They represent important information for the further development of integrated care in Switzerland, and should help identify areas requiring attention for a successful transformation of the Swiss healthcare system towards more integrated care.

\section{INTRODUCTION}

Since the late 1990s, healthcare systems have been facing the challenge of preventing and managing chronic diseases and their related societal and individual burden. Since then, integrated care has emerged as a way to overcome
Strengths and limitations of this study

- The Scaling Integrated Care in Context (SCIROCCO) maturity model tool is a validated instrument targeting the maturity of healthcare system for integrated care, the results of which may support the implementation and further expansion of integrated care at the system and organisational level.

- The SCIROCCO tool has not been previously used at a nationwide level; in Switzerland, more than 600 healthcare stakeholders took part in a national electronic survey.

- We used the SCIROCCO tool in conditions different than those in which it was originally developed, without the consensus-like method which encourages discussion and sharing of experiences among smaller groups of key participants; the latter may also allow a common understanding and interpretation of the content of the dimensions and response modalities.

- Due to the complexity of the Swiss health system, individual respondents of a large-scale survey may lack comprehensive knowledge of all dimensions.

the overall fragmentation of healthcare services, ${ }^{1}$ and various initiatives have been implemented across and within countries. ${ }^{2}$ Despite common overall goals, often aligned with the triple aim (ie, population health, quality of care/care experiences, costs), ${ }^{3}$ integrated care initiatives are very heterogeneous because of their context dependency. ${ }^{4}$ In fact, they often differ in terms of target populations, type of healthcare professionals and healthcare system levels involved, scope, components and size, among others. Additionally, integrated care initiatives often remain at the pilot stage as they present scaling up difficulties and limited transferability and replicability. ${ }^{2}$ For these reasons, understanding barriers and facilitators of the implementation and scaling up of integrated care programmes has been the focus of several comprehensive European projects. $^{5-10}$ 
In Europe, the degree and extent of development of integrated care initiatives varies greatly between countries. ${ }^{2}$-10 While some countries such as the UK, the Netherlands and Spain often are considered as early adopters for developing large-scale integrated care for more than three decades, other countries such as Switzerland and Belgium seem to have developed less visible or more recent large-scale innovations. ${ }^{11}{ }^{12}$ To support stakeholders in their endeavour towards better integrated care, a conceptual maturity model was developed on the basis of qualitative interviews conducted with health and social care delivery organisations from across 12 European countries and regions. ${ }^{13}$ Results were categorised into 12 dimensions considered key to deliver integrated care: 'Readiness to Change'; 'Structure and Governance'; 'eHealth Services'; 'Standardisation and Simplification'; 'Funding'; 'Removal of Inhibitors'; 'Population Approach'; 'Citizen Empowerment'; 'Evaluation Methods'; 'Breadth of Ambition'; 'Innovation Management'; 'Capacity Building'. Further on, the maturity model was validated and developed into an online self-assessment tool for integrated care through a European Union-funded project (SCIROCCOScaling Integrated Care in Context). ${ }^{14}$ The aim of this tool is to 'comprehensively assess the maturity of the progress of a regional system uncovering its strengths, weaknesses and areas for improvement in the development of integrated care delivery'. ${ }^{1516}$ As such, it may support the implementation and further expansion of integrated care at the system and organisational level. Up to now, the assessment of integrated care with the SCIROCCO tool has been conducted at regional levels, and mostly within the context of the SCIROCCO project. ${ }^{17}{ }^{18}$ Integrated care being very context dependent, assessing maturity of healthcare integration at a regional level, makes sense. However, since healthcare may be organised both at national and regional levels, assessing maturity at a country level could also help inform healthcare policymakers about areas of improvement that might be the target of nationwide actions. This may be particularly crucial in federal countries such as Switzerland, which decentralise healthcare responsibilities and lack restrictive national health policies and legal frameworks to ease the quicker and larger scale development of integrated care. Concretely realising where gaps lie may motivate healthcare policymakers to act. To our knowledge, a nationwide evaluation using the SCIROCCO tool has not been performed yet. Using that tool, we aimed to: first, assess the maturity of the Swiss healthcare system for integrated care; and second, explore whether maturity assessed by the SCIROCCO tool varied according to working linguistic regions (German, French, Italian), or according to the profession of, or position held by, the respondents.

\section{METHODS}

\section{Study design, population and setting}

In November 2019, we conducted an online survey across Switzerland, which link was sent to integrated care stakeholders. Eligible participants were purposefully selected on the basis of their potential knowledge and experience in the field of integrated care. This was done using lists of stakeholders of both the FMC, the Swiss Forum for integrated Care, and the integrated care unit of the Swiss Federal Office of Public Health; we also included representatives of the 26 cantonal public health departments. An email invitation to participate in the electronic survey was sent to approximately 5500 healthcare stakeholders spread across Switzerland; 2 weeks later, we sent a reminder to non-respondents.

\section{Measures}

The main dependent variable of this study is the maturity of the Swiss healthcare system for integrated care, measured with the SCIROCCO tool, ${ }^{14-16}$ which comprises the following 12 dimensions: 'Readiness to Change'; 'Structure and Governance'; 'eHealth Services'; 'Standardisation and Simplification'; 'Funding'; 'Removal of Inhibitors'; 'Population Approach'; 'Citizen Empowerment'; 'Evaluation Methods'; 'Breadth of Ambition'; 'Innovation Management'; 'Capacity Building'. Each of the 12 dimensions presents first a brief description of the dimension, followed by the response modalities according to a 6-point scale, ranging from 0 (equivalent to 'not fulfilled', 'not present/available') to 5 (equivalent to 'fully fulfilled', 'totally present/available') (table 1). Using data from seven European countries, this tool has shown good content validity, as well as a one-factor structure with good internal consistency. ${ }^{16}$ Because French and German versions of the tool did not exist at the time of the survey preparation, we translated and culturally adapted the SCIROCCO version using the following pragmatic approach. First, two pairs of persons (one professional translator and one English-native collaborator fluent in French and German, respectively) prepared French and German versions of the questionnaire that were then discussed by a group of experts. After reaching consensus on the first French and German versions, the tool was pretested among a dozen of German-speaking and French-speaking healthcare stakeholders. The expert group then resolved discrepancies and agreed on final German and French versions of the SCIROCCO tool. The Italian version of the tool used in Switzerland was updated from the already existing Italian SCIROCCO tool. During the whole translation process, cross-checks across the three versions were made to ensure content consistency and homogeneous understanding of the questions. All three versions of the SCIROCCO tool are available in the online supplemental file 1.

The other variables included in the survey were: respondents' age (continuous) and gender (men/women), type of healthcare profession (six categories: practising physicians, non-physician practising healthcare professionals, directors, administration, project management, other), main setting of professional activity (nine categories: independent, public administration, foundation/association, insurance, private clinic, university hospital, cantonal hospital, medical home, other) and working linguistic region (German-speaking Switzerland, French-speaking 
Table 1 Description of the 12 dimensions of the SCIROCCO tool

\section{Dimensions Objectives}

Readiness to Change Providing a more integrated set of services by creating new roles, processes and working practices, as well as new systems to support information sharing and collaboration across care teams.

Structure and

Governance

Multiyear programmes with efficient change management, funding and communication, and the or national level.

eHealth Services Building on existing eHealth services, connecting them in new ways to support integration, and augmenting them with new capabilities (enhanced security and mobility) will enable continuous collaboration, measuring and managing outcomes, and citizens will take a more active role in their care.

Standardisation and Simplification

Simplification of the number of different systems in use and the formats in which they store data by consolidating data centres, standardising on fewer systems and agreeing on what technical standards will be used across a region or country.

Funding Initial investment and funding are required to change systems of care so that they can offer better integration. To ensure that the initial and ongoing costs can be financed, a full range of mechanisms from regional/national budgets to 'stimulus' funds, public-private partnerships and risk-sharing mechanisms need to be used.

Removal of Inhibitors Funded programmes and good eHealth infrastructure can face barriers (legal issues with data governance, resistance to change from individuals or professional bodies, cultural barrier to the use of technology, perverse financial incentives and lack of skills), which need to be recognised early in order to develop a plan to deal with them and to minimise their impact.

Population Approach Integrated care can be developed to benefit citizens who are not thriving under existing systems of care, in order to help them manage their health and care needs in a better way, and to avoid emergency calls and hospital admissions and reduce hospital stays. That way, the citizens can maintain their health for longer and be less dependent on care services as they age.

Citizen Empowerment Easy-to-use services, such as appointment booking, self-monitoring of health status and alternatives to medical appointments, need to be available to citizens, as they are willing to do more to participate in their own care, as suggested by evidence. This means providing services and tolls that enable convenience, offer choice, and encourage self-service and engagement in health management, considering the need to address the risk of health and social inequalities.

Evaluation Methods Evidence-based investment is required, meaning that the impact of each change is evaluated. Health technology assessment is an important method here and can be used to justify the cost of scaling up of integrated care to regional or national level.

Breadth of Ambition Integrated care includes many levels of integration, such as integration between primary and secondary care, of all stakeholders involved in the care process, or across many organisations. The long-term goal should be fully integrated care services, which provide a complete set of seamless interactions for the citizen, leading to better care and improved outcomes.

$\begin{array}{ll}\begin{array}{l}\text { Innovation } \\ \text { Management }\end{array} & \text { Managing the innovation process to get the best results for the systems of care and ensuring that } \\ \text { good ideas are encouraged and rewarded, is necessary. Innovations from clinicians, nurses and } \\ \text { social workers need to be recognised and scaled up to provide benefit across the system as well as } \\ \text { taking into consideration universities and private sector companies, which are increasingly willing } \\ \text { to engage in open innovation in order to develop new technologies, test process improvements and } \\ \text { deliver new services that meet the needs of citizens. There is also value in looking outside the system } \\ \text { to other regions and countries that are dealing with the same set of challenges, to learn from their } \\ \text { experiences. }\end{array}$

SCIROCCO, Scaling Integrated Care in Context.

Switzerland, Italian-speaking Switzerland, nationwide). Participants were also asked to indicate whether they had been, or were currently involved, in an integrated care initiative (three categories: no, never; yes, once; yes, several times). For those involved in such initiatives, an additional question asked about their role in them (seven 
categories: executive; coordinator; healthcare provider; project leader; case manager; administrative or financial administrator; other). Finally, we enquired about the participants' opinion towards integrated care (nine items: eg, 'integrated care is the best option for patient-centred care'; 'integrated care is efficient in terms of health costs'; 'integrated care is just one care option among many') and about their general opinion towards the Swiss healthcare system (single item adapted from the Swiss version of the 2016 International Health Policy Survey of the Commonwealth Fund). ${ }^{19} 20$

\section{Statistical analyses}

We performed cross-sectional analyses on our survey data. First, we ran univariate analyses to describe the characteristics of the respondents and responses to each dimension, considering frequencies and percentages for categorical variables as well as means and SDs for continuous variables. Then, we performed bivariate analyses to find out whether maturity for integrated care, as measured by the 12 dimensions of the SCIROCCO tool, varied according to the stratified variables. For the region of professional activity (nationwide; German-speaking Switzerland; French-speaking Switzerland), Italian-speaking Switzerland was not kept as a category because the number of respondents was too small. The bivariate analyses therefore considered the working linguistic region, the type of healthcare profession, the main setting of professional activity of the respondents, their role in integrated care initiatives, if any, and their participation in integrated care initiatives. Associations between the answers on the 12 dimensions of the SCIROCCO tool and the respondents' attitude towards integrated care and towards the Swiss healthcare system were tested using Pearson's correlations. Statistical analyses were performed using SPSS V.25 and STATA V.16.0.

\section{Patient and public involvement}

Healthcare and integrated care stakeholders helped to adapt the German and French versions of the SCIROCCO tool. Stakeholders and representatives were the main informants of the results of our study, through their participation and responses to the survey. Patients were not explicitly involved.

\section{RESULTS}

Approximately one out of six persons contacted answered the questionnaire $(n=642)$. Their characteristics are presented in table 2 . The mean age of respondents was 53.7 years $( \pm 10.5)$ and $42.5 \%$ were women. Approximately one-third and a quarter of the respondents were healthcare providers (physicians and non-physicians) and directors of institutions, respectively. In addition, a little less than half were working in healthcare institutions. Respondents were mainly professionally active in the German-speaking part of Switzerland (60.0\%), the others worked in the French-speaking Switzerland (20.7\%) or

\begin{tabular}{|c|c|c|}
\hline Variables & (n) & Mean (SD) or $\%$ \\
\hline Age & (610) & $53.7(10.5)$ \\
\hline Women & $(617)$ & 42.5 \\
\hline Profession & (625) & \\
\hline Practising physicians & & 19.8 \\
\hline $\begin{array}{l}\text { Non-physician practising } \\
\text { healthcare professionals }\end{array}$ & & 16.0 \\
\hline Directors & & 27.7 \\
\hline Administration & & 9.6 \\
\hline Project management & & 15.4 \\
\hline Other & & 11.5 \\
\hline Professional activity & (597) & \\
\hline Independent & & 19.4 \\
\hline Public administration & & 11.6 \\
\hline Foundation/association & & 12.2 \\
\hline Insurance & & 5.7 \\
\hline Private clinic & & 3.2 \\
\hline University hospital & & 22.1 \\
\hline Cantonal hospital & & 11.2 \\
\hline Medical home & & 9.2 \\
\hline Other & & 5.4 \\
\hline Working linguistic region & $(627)$ & \\
\hline $\begin{array}{l}\text { German-speaking } \\
\text { Switzerland }\end{array}$ & & 60.0 \\
\hline $\begin{array}{l}\text { French-speaking } \\
\text { Switzerland }\end{array}$ & & 20.7 \\
\hline Italian-speaking Switzerland & & 3.2 \\
\hline Nationwide & & 16.1 \\
\hline Implication in integrated care & (628) & \\
\hline No, never & & 46.5 \\
\hline Yes, once & & 18.8 \\
\hline Yes, several times & & 34.7 \\
\hline $\begin{array}{l}\text { Attitude towards the Swiss } \\
\text { healthcare system }\end{array}$ & (610) & \\
\hline Complete change needed & & 8.2 \\
\hline Major changes & & 76.9 \\
\hline Minor changes & & 14.9 \\
\hline
\end{tabular}

across the country $(16.1 \%)$. Whereas respondents were working in all 26 Swiss cantons, 7 cantons had more than 20 participants: Zurich $(\mathrm{n}=121)$, Bern $(\mathrm{n}=91)$, Vaud $(\mathrm{n}=53)$, St-Gall $(\mathrm{n}=35)$, Argau $(\mathrm{n}=28)$, Lucern $(\mathrm{n}=26)$, Basel city $(n=21)$. Just over half of the respondents took part in integrated care activities.

Overall, over a $0-5$ rating scale, mean ratings were on the lower side, with 7 out of 12 dimensions having means lower than 2 ('Readiness to Change'; 'Structure and Governance'; 'Standardisation and Simplification', 'Funding'; 'Breadth of Ambition'; 'Innovation 


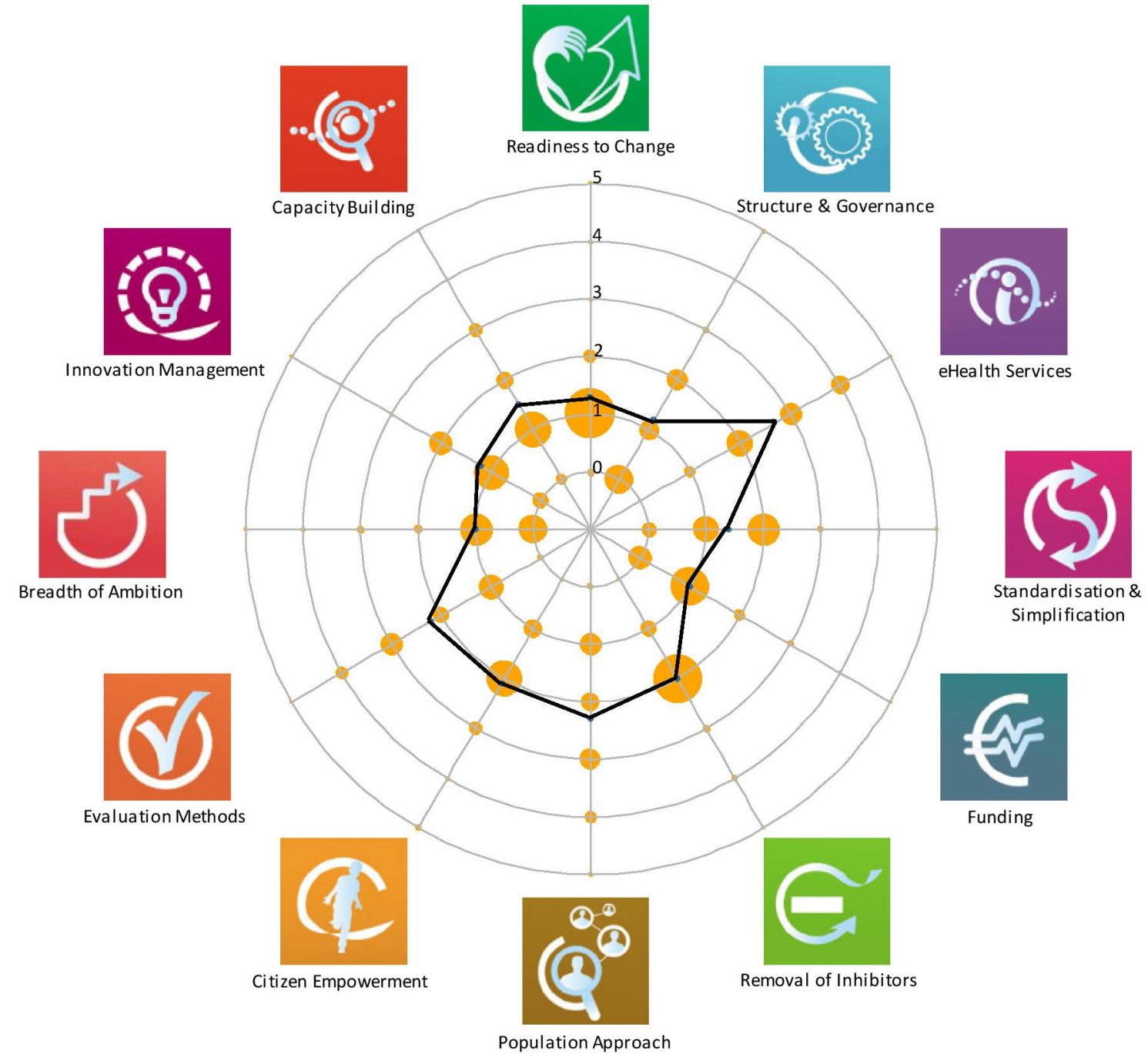

Figure 1 Spider graph representing means (dark line) and proportions (dots) of each response category, by dimension (dots are proportionate to the number of responses for each response category).

Management'; 'Capacity Building') and dimensions' means varying between a minimum of 1.0 (two dimensions: 'Funding'; 'Breath of Ambition') and a maximum of 2.7 (one dimension: 'eHealth Services') (see figure 1 and table 2 for details). As illustrated in figure 1 and table 3, which show the distributions of the individual responses, the span of responses varied across dimensions. Whereas dimensions 6 ('Removal of Inhibitors') and 10 ('Breadth of Ambition') concentrated the majority of responses on two response modalities, all the other dimensions showed a spread of responses over three or four response modalities.

Subgroup analyses did not show significant differences, except between working linguistic regions: compared with respondents working in the German-speaking part of Switzerland or working across the country (ie, 'nationwide' category), persons working in the French-speaking part of Switzerland gave lower ratings to the 'Population Approach', 'Citizen Empowerment' and 'Evaluation Methods' dimensions and higher ones to the 'Readiness to Change' and 'Structure and Governance' dimensions.
Additionally, notwithstanding the fact that answers from the same canton were very much spread across the whole range of modalities, the distribution of ratings across cantons presented some particularities. For example, while the distributions were very much similar for the dimensions of 'Readiness to Change' and 'Capacity Building', they were more heterogeneous for the dimensions of 'Population Approach' (range 0-4) and 'eHealth Services' (range 2-4) (figure 2).

Finally, attitudes toward integrated care and attitudes toward the Swiss healthcare system did not show strong associations with the 12 dimensions (correlations ranging from -0.35 to 0.16 and from -0.06 to 0.17 , respectively).

\section{DISCUSSION}

The results of this nationwide survey show that overall, the 'maturity' of the Swiss healthcare system for integrated care, as assessed using the SCIROCCO tool, was rated on the lower side. Whereas the 'Funding' dimen-

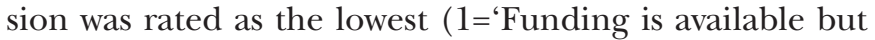




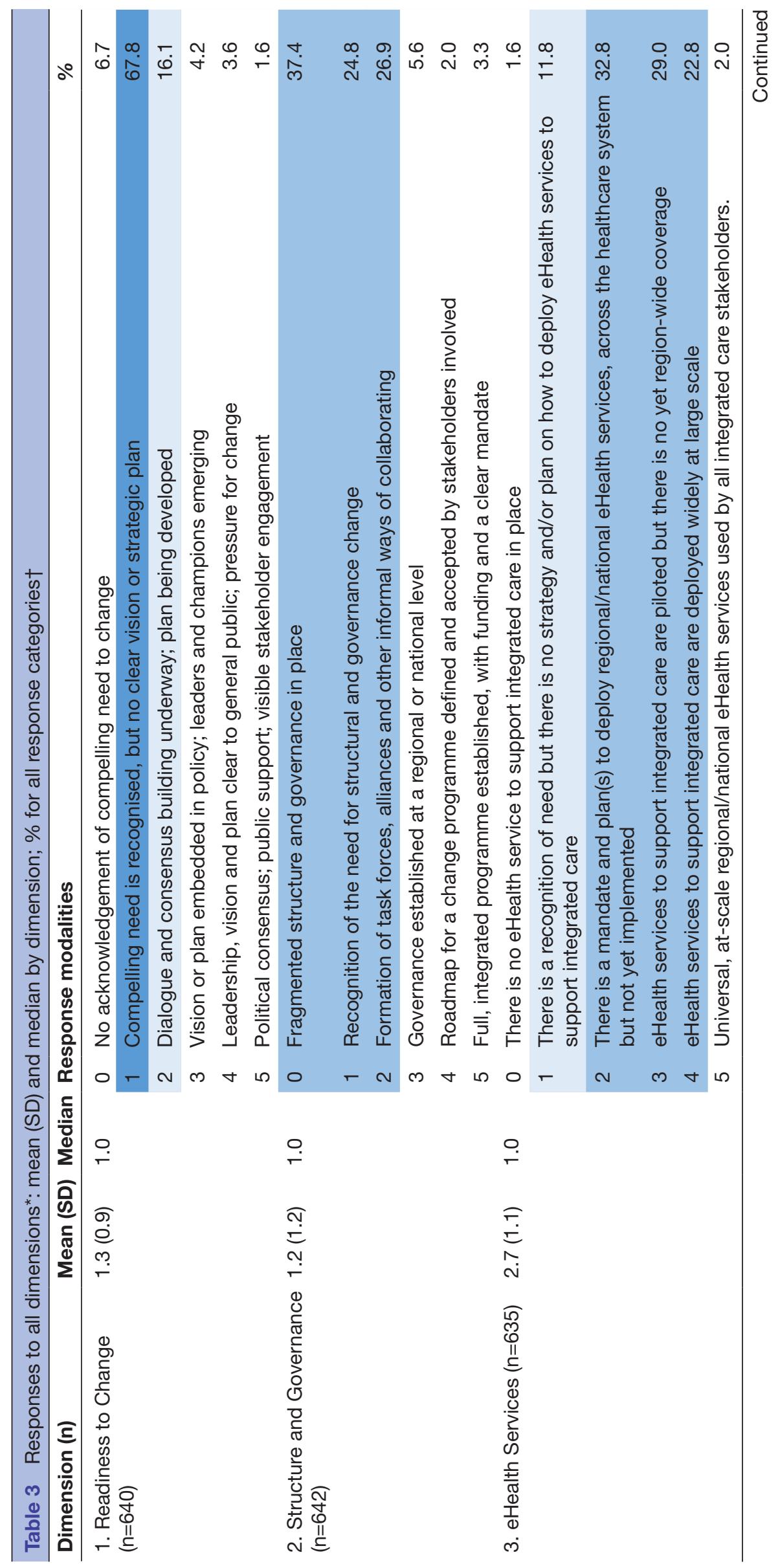




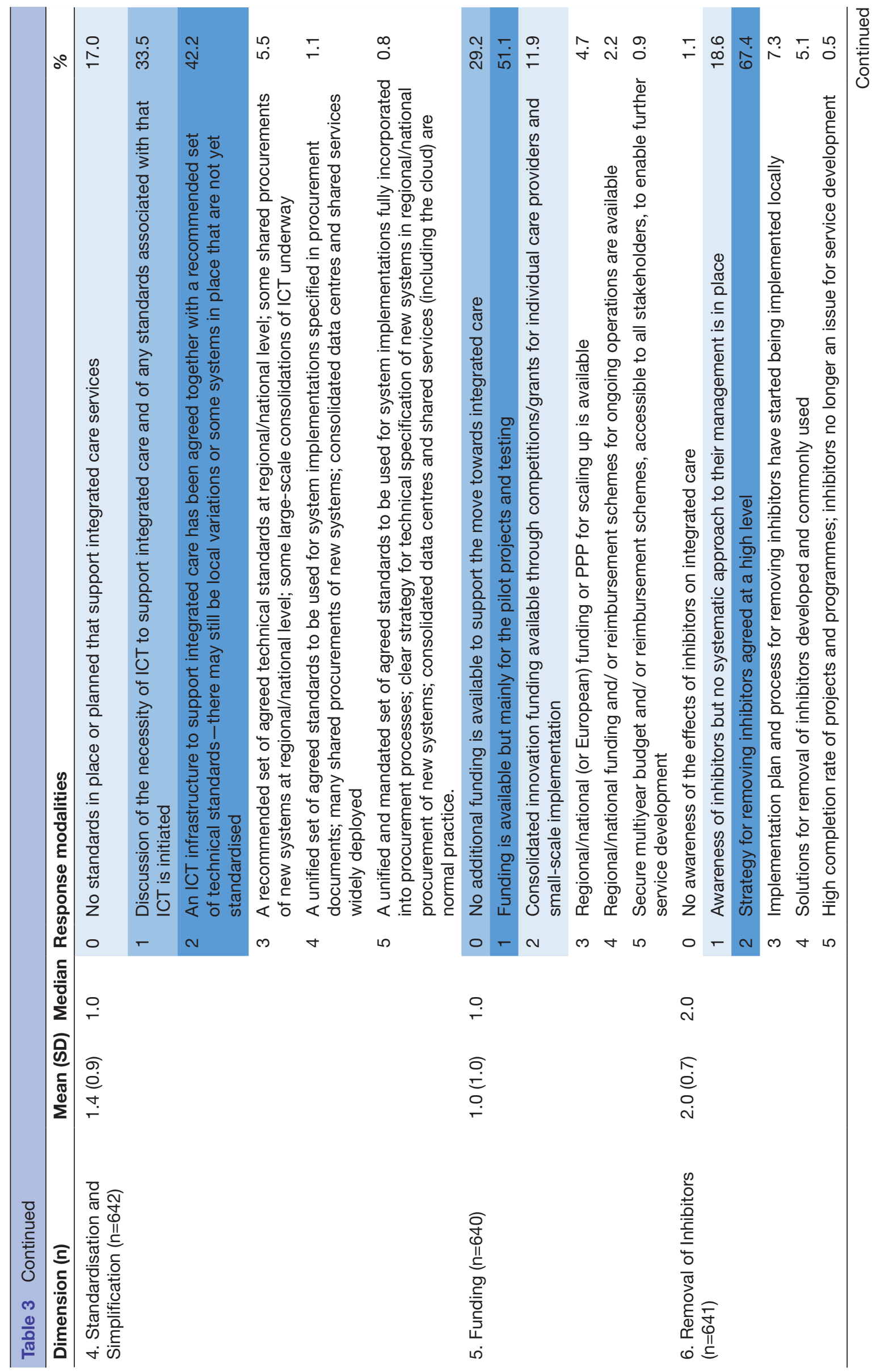

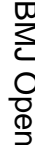




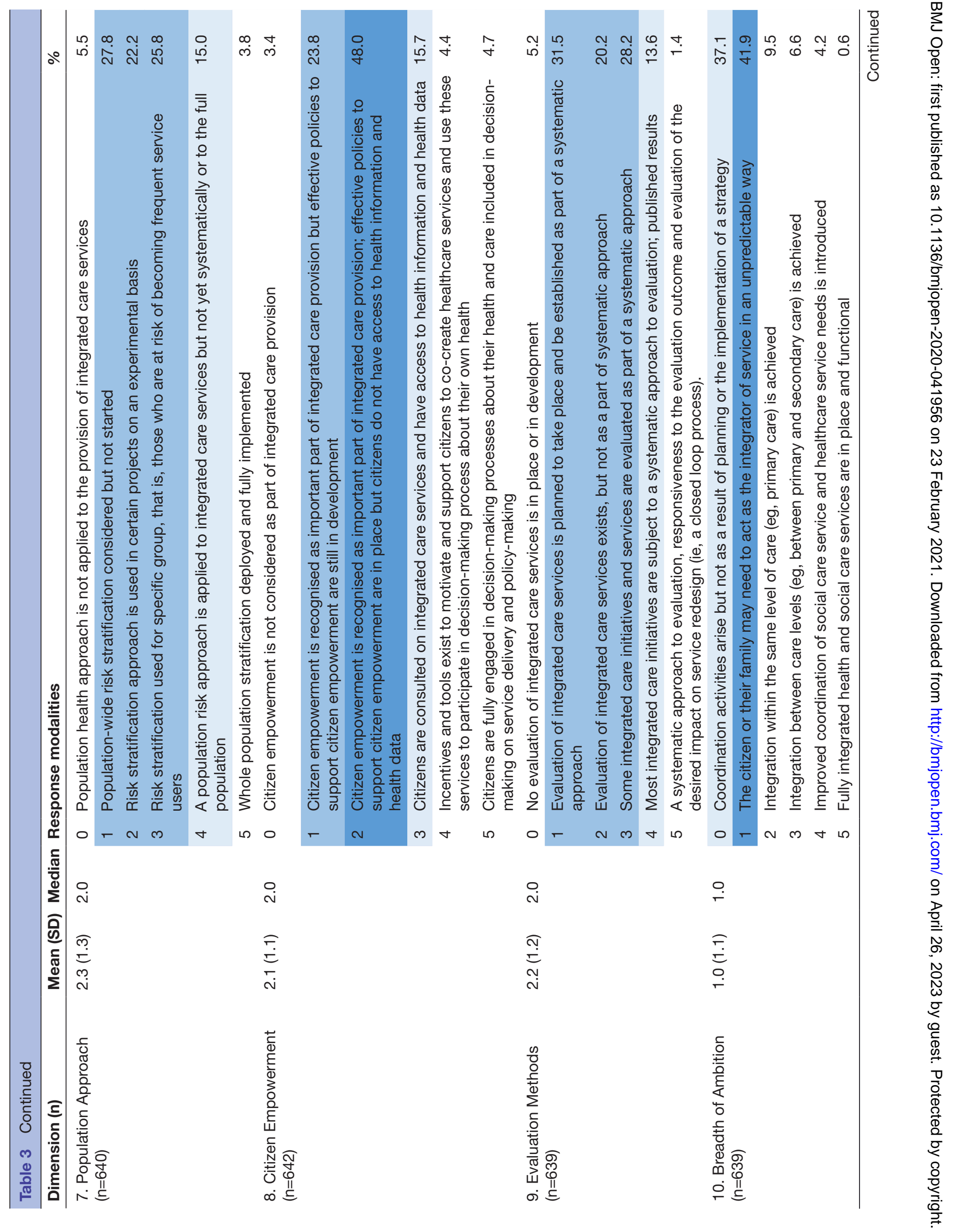




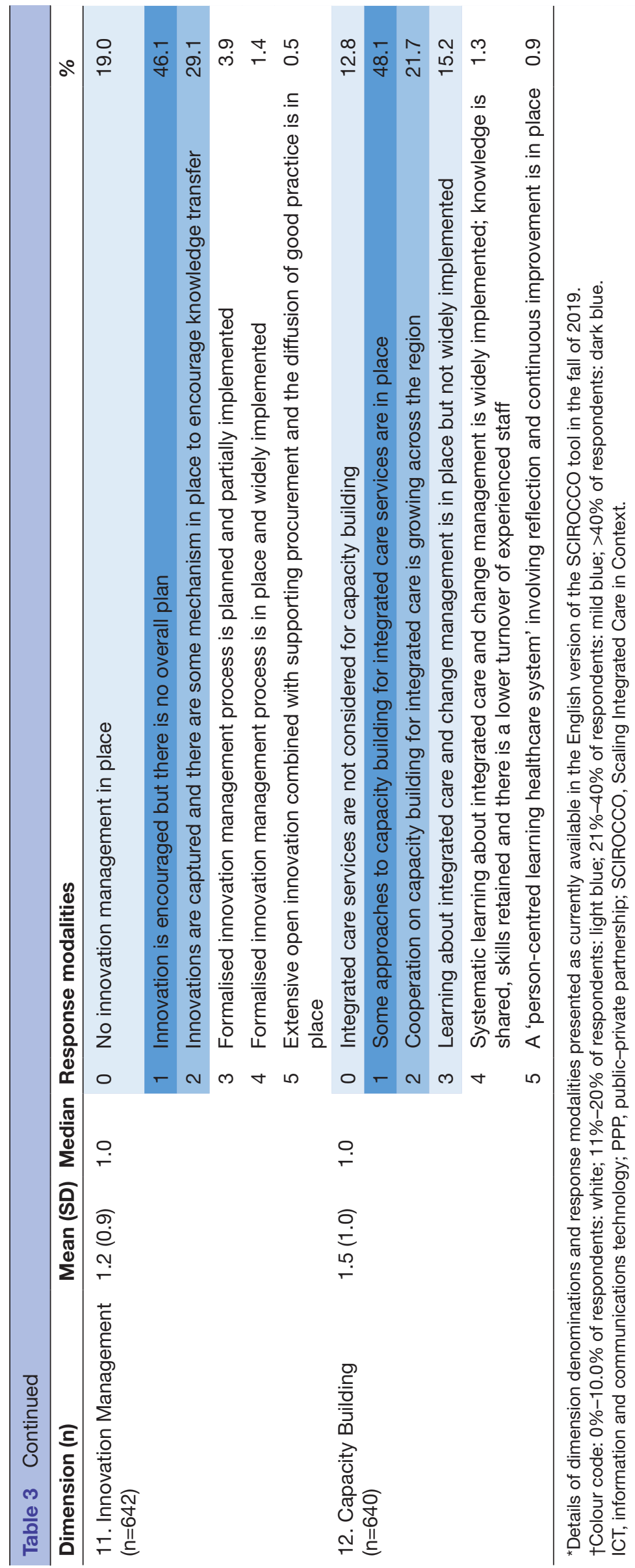



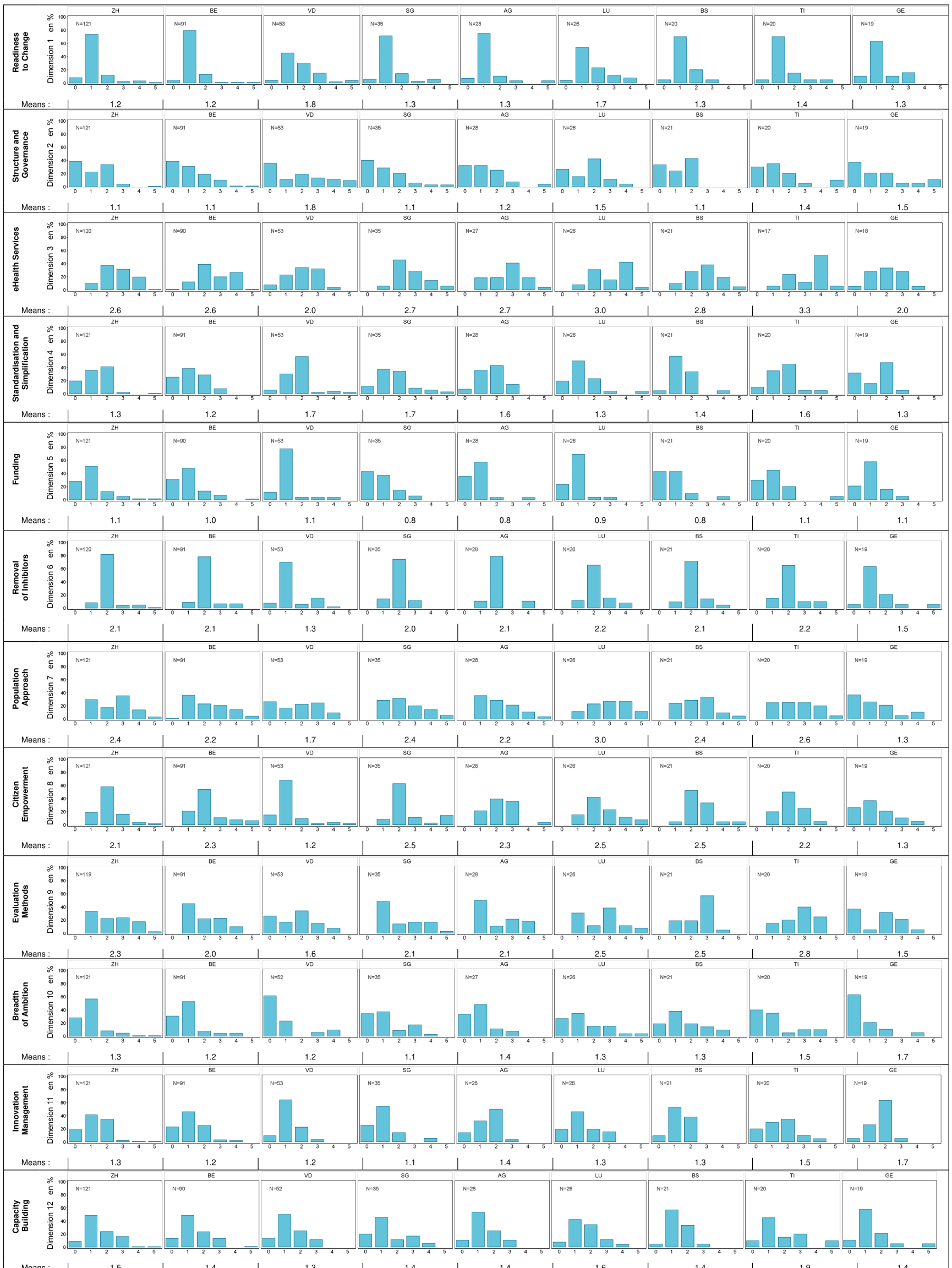

Figure 2 Histograms presenting, by dimension, the distribution of ratings of the nine cantons with the highest number of respondents. AG, Argovie; BE, Bern; BS, Basel; GE, Geneva; LU, Lucern; SG, St-Gall; TI, Ticino; VD, Vaud; ZH, Zurich. 
mainly for the pilot projects and testing'), the 'Information and eHealth Services' dimension had the highest rating ( $3=$ 'eHealth Services to support integrated care are piloted but there is no yet region-wide coverage'). Additionally, an important span of ratings was observed for several dimensions. Nevertheless, variations in ratings between working linguistic regions varied only slightly and were limited to a few dimensions.

In comparison with other European countries or regions, such as Scotland, Italy, the Netherlands or the Basque Country, ${ }^{17}$ where maturity measures were performed at local levels, the maturity of the Swiss healthcare system for integrated care seems to fall behind for some dimensions of the SCIROCCO tool. ${ }^{17}$ However, even though these countries and regions have a long tradition of integrated care, they do not rate high on all dimensions either. The low maturity results of Switzerland call for stronger policies targeting all SCIROCCO dimensions. Some have been introduced recently, for example the 2020-2030 Health Policy Strategy ${ }^{21}$ issued in December 2019, which targets care coordination, digitalisation of health and health literacy. Additionally, democratic consultations regarding various adaptations of the health insurance law, which address numerous elements included in the SCIROCCO tool, such as eHealth and financing and funding of integrated care services, have been launched in the summer of 2020. These initiatives should support the development of integrated care in Switzerland in the near future.

The low maturity ratings of the Swiss health system can be explained by the fact that the organisation of integrated care and healthcare in general, is not centralised. Indeed, Switzerland is a federal country with a complex division of tasks and funding between the federal and cantonal levels, as well as between all actors of the healthcare system. For instance, each canton is responsible for securing healthcare provision for its own population. ${ }^{22}$ This complexity and fragmentation of the Swiss health system prevents rapid and large-scale development of integrated care ${ }^{23-25}$; Schusselé Fillietaz, personal communication 15 December 2020). However, the federal organisation of healthcare leaves considerable room for the implementation of local initiatives, which may need to be considered since large-scale strategies do not always represent the optimal option. ${ }^{26}$ Results of the national integrated care survey conducted in 2015-2016 showed that local integrated care initiatives have been steadily growing in Switzerland over the last 20 years and were characterised by a diversity of types and breadth of initiatives, implemented interventions and targeted population, among others. ${ }^{11}$ Therefore, the low maturity results according to the SCIROCCO tool probably reflect a limited maturity for integrated care at the federal level rather than the cantonal one.

Within this low Swiss health system maturity context, the rating differences observed between working linguistic regions of the SCIROCCO evaluation could be explained as follows: respondents may have found it difficult to keep in mind the situation of the whole country and not to be influenced by their own specific experiences and local contexts when rating health system maturity, especially considering the existing heterogeneity of integrated care initiatives between the different regions. ${ }^{11}$

Obtaining responses to this survey from a large sample size of various healthcare stakeholders from across the country represents the main strength of this study. Nevertheless, results should be interpreted with the following two limitations in mind. First, our methodological approach used the SCIROCCO tool in different conditions than the ones in which it was developed. Originally, dimensions are rated individually by regional stakeholders and results are then discussed in small consensus groups to obtain one single (consensual) value for each dimension. In our survey, we used an online approach and obtained one mean value for each dimension. Compared with the latter (ie, a single individual in front of an online survey), it is possible that the consideration of small groups of stakeholders sharing specific expertise in all aspects of the healthcare system allows to obtain a deeper knowledge of the aspects considered in the SCIROCCO tool. In fact, small groups discussions may favour reaching a common understanding and interpretation of the content of the dimensions and response modalities, possibly leading to a higher (more optimistic) rating. Second, even though attention and rigour were given to the adaptation and translation processes for the different versions of the tool for each linguistic region, wording differences cannot be excluded and may have had an effect on the regional differences found.

\section{CONCLUSION}

Our findings reflect an overall limited maturity of the Swiss healthcare system for integrated care, as evaluated with the SCIROCCO tool at a national level by a large variety and number of healthcare stakeholders. Despite the need for a cautious interpretation of the results, they represent the first maturity-related information for further development of integrated care in Switzerland. As such, findings suggest that further support is needed for a successful evolution of the system towards more integrated care, by identifying areas requiring attention. Future research or use of the SCIROCCO tool should try assessing maturity both at system and regional levels and combining discussions and the sharing of experiences at the level where integrated care is concretely developed and implemented, by keeping in mind systemic constraints or facilitators.

Acknowledgements We thank Chantal Arditi, Federico Cathieni, Anita Savidan, Lea von Wartburg, Adriana de Giorgi, Tania Weng Bornholt, Urs Zanoni for their participation in the SCIROCCO adaptation-translation process, and all respondents who took part in the survey. We also thank Tapio Niemi who kindly prepared Figure 1.

Contributors IP-B and IG designed and conducted the study, with help from MG. IP-B, SSF, PB, MG and IG were involved in the SCIROCCO adaptation-translation process. Whereas IG and IP-B carried out the analysis, IP-B, SSF, PB, MG, AP and IG 
interpreted the data and participated in the writing of the paper, which was led by IP-B. All authors revised the paper and approved the final version.

Funding The authors have not declared a specific grant for this research from any funding agency in the public, commercial or not-for-profit sectors.

Competing interests None declared.

Patient consent for publication Not required.

Provenance and peer review Not commissioned; externally peer reviewed.

Data availability statement Data are available upon reasonable request. The datasets used during the study are available from the corresponding author on reasonable request.

Supplemental material This content has been supplied by the author(s). It has not been vetted by BMJ Publishing Group Limited (BMJ) and may not have been peer-reviewed. Any opinions or recommendations discussed are solely those of the author(s) and are not endorsed by BMJ. BMJ disclaims all liability and responsibility arising from any reliance placed on the content. Where the content includes any translated material, BMJ does not warrant the accuracy and reliability of the translations (including but not limited to local regulations, clinical guidelines, terminology, drug names and drug dosages), and is not responsible for any error and/or omissions arising from translation and adaptation or otherwise.

Open access This is an open access article distributed in accordance with the Creative Commons Attribution Non Commercial (CC BY-NC 4.0) license, which permits others to distribute, remix, adapt, build upon this work non-commercially, and license their derivative works on different terms, provided the original work is properly cited, appropriate credit is given, any changes made indicated, and the use is non-commercial. See: http://creativecommons.org/licenses/by-nc/4.0/.

\section{ORCID iDs}

Isabelle Peytremann-Bridevaux http://orcid.org/0000-0002-6514-8781

Séverine Schusselé Filliettaz http://orcid.org/0000-0001-7475-1120

\section{REFERENCES}

1 Goodwin N. Understanding integrated care. Int J Integr Care 2016;16.

2 Amelung V, Stein V, Goodwin N, eds. Handbook integrated care. 1st ed. Cham (Switzerland): Springer, 2017:595.

3 Berwick DM, Nolan TW, Whittington J. The triple aim: care, health, and cost. Health Aff 2008;27:759-69.

4 Hawe P. Lessons from complex interventions to improve health. Annu Rev Public Health 2015;36:307-23.

5 VIGOUR. Evidence-based guidance to scale-up integrated care in Europe, 2020. Available: https://vigour-integratedcare.eu/

6 Project Integrate. Project integrate, 2020. Available: http://www. projectintegrate.eu.com/

7 SUSTAIN. Sustainable tailored integrated care for older people in Europe. sustain is a cross-European research project and stands for sustainable tailored integrated care for older people in Europe, 2020. Available: https://www.sustain-eu.org/
8 Selfie. Sustainable integrated care models for multi-morbidity delivery, financing and performance [Internet]. The Netherlands, 2020. Available: https://www.selfie2020.eu/

9 ICARE4EU. Innovating care for people with multiple chronic conditions in Europe, 2020. Available: http://www.icare4eu.org/

10 DISMEVAL. Developing and validating disease management evaluation methods for European health care systems. Cambridge: Rand Europe, 2020. http://www.dismeval.eu/

11 Schusselé Filliettaz S, Berchtold P, Kohler D, et al. Integrated care in Switzerland: results from the first nationwide survey. Health Policy 2018;122:568-76.

12 INTEGREO. Des soins intégrés pour une meilleure santé, 2020. Available: https://www.integreo.be/fr/projets-pilotes/planning

13 European Innovation Partnership. A maturity model for adoption of integrated care within regional healthcare systems (B3 action group), 2020. Available: https:// ec.europa.eu/eip/ageing/repository/ maturitymodel-adoption-integrated-care-within-regionalhealthcaresystems-b3-action_en

14 Grooten L, Vrijhoef HJM, Calciolari S, et al. Assessing the maturity of the healthcare system for integrated care: testing measurement properties of the SCIROCCO tool. BMC Med Res Methodol 2019;19:63.

15 Grooten L, Borgermans L, Vrijhoef HJ. An instrument to measure maturity of integrated care: a first validation study. Int $J$ Integr Care 2018;18:10.

16 Pavlickova A. SCIROCCO tool to support delivery of integrated care in Europe. Int J Integr Care 2017;17:504.

17 Scirocco. Regions' self-assessment, 2016. Available: https://www. scirocco-project.eu/regions-self-assessment/

18 Pavlickova A. SCIROCCO tool to support delivery of integrated care in Europe. Int J Integr Care 2017;17:A504.

19 The Commonwealth Fund. 2016 Commonwealth fund international health policy survey of adults, 2020. Available: https://www. commonwealthfund.org/publications/surveys/2016/nov/2016commonwealth-fund-international-health-policy-survey-adults

20 Osborn R, Squires D, Doty MM, et al. In new survey of eleven countries, US adults still struggle with access to and affordability of health care. Health Aff 2016;35:2327-36.

21 Federal office of public health. Politique de la santé : stratégie du Conseil fédéral 2020-2030 [Health policy: Federal Council's strategy 2020-2030. Switzerland: Federal Office of Public Health FOPH, 2019. https://www.bag.admin.ch/bag/fr/home/strategie-und-politik/ gesundheit-2030/gesundheitspolitische-strategie-2030.html

22 De Pietro C, Camenzind P, Sturny I, et al. Switzerland: Health System review. Health Syst Transit 2015;17:1-288.

23 Lauvergeon S, Burnand B, Peytremann-Bridevaux I. Chronic disease management: a qualitative study investigating the barriers, facilitators and incentives perceived by Swiss healthcare stakeholders. BMC Health Serv Res 2012;12:176.

24 Berchtold P, Peytremann-Bridevaux I. Ten years of integrated care in Switzerland. Int J Integr Care 2011;11:Spec Ed:e010.

25 OECD. OECD/WHO (2011), OECD reviews of health systems: Switzerland 2011. OECD Publishing, 2020. http://dx.doi.org/10.1787/ 9789264120914-en

26 Hughes G, Shaw SE, Greenhalgh T. Rethinking integrated care: a systematic hermeneutic review of the literature on integrated care strategies and concepts. Milbank Q 2020;98:446-92. 